Elsevier

GEN 02282

\title{
Interaction of tRNA transcription factors with satellite I DNA from Xenopus laevis
}

(Recombinant DNA; DNA binding proteins; yeast RNA polymerase III; repetitive class III promoters; footprinting)

\section{David R. Engelke}

Department of Biological Chemistry, University of Michigan, Ann Arbor, MI 48109 (U.S.A.) Tel. (313)763-0641

Received 28 July 1987

Revised 13 October 1987

Accepted 14 October 1987

Received by publisher 11 November 1987

\section{SUMMARY}

A cloned repeat of Xenopus laevis satellite I DNA was tested for the ability to form stable complexes with tRNA transcription factors in vitro. In template exclusion studies, the satellite I DNA competed efficiently with a tRNA gene for binding of yeast RNA polymerase III transcription factors. DNase I footprinting further showed that transcription factor TF IIIC alone bound to satellite I DNA at both the A block and B block consensus promoter sequences immediately downstream from the transcription start point. The strength and position of these associations indicate that satellite I DNA is a potential site for association of the same DNA-binding proteins that activate tRNA gene transcription.

\section{INTRODUCTION}

Satellite I DNA from Xenopus laevis is a highly reiterated element of $741 \mathrm{bp}$ that exists as dispersed tandem clusters (Lam and Carroll, 1983). Sequence analysis of independently isolated repeats (Lam and Carroll, 1983; Ackermann, 1983) revealed the

Correspondence to: Dr. D.R. Engelke, Department of Biological Chemistry, University of Michigan, Medical Science I, Ann Arbor, MI 48109 (U.S.A.) Tel. (313) 736-0640.

Abbreviations: bp, base pair(s); $\Delta$, deletion; nt, nucleotide(s); PA, polyacrylamide; SDS, sodium dodecyl sulfate; TF, transcription factor. presence of appropriately spaced DNA segments homologous to the conserved $5^{\prime}$ and $3^{\prime}$ internal promoter elements (A and B blocks) found in eukaryotic tRNA genes (Traboni et al., 1982; Sharp et al., 1981) and other highly repetitive eukaryotic sequence elements (Duncan et al., 1979; Elder et al., 1981; Fuhrman et al., 1981; Fritsch et al., 1981; PerezStable et al., 1984, Sutcliffe et al., 1984). Transcription of the cloned satellite DNA by cellular extracts and by injection into Xenopus oocytes (Ackerman, 1983; Wakefield et al., 1983; Andrews et al., 1984) has confirmed that these promoter elements do, in fact, compete for the binding of RNA polymerase III transcription factors and direct transcription initiation immediately upstream from the A 


\section{E 190 \\ $\underline{X}$. laevis Satellite I DNA \\ 741 bp repeat}

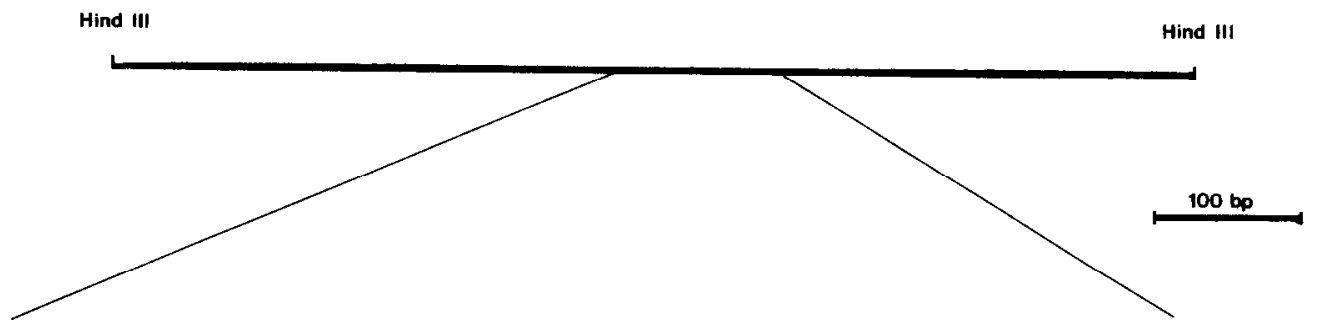

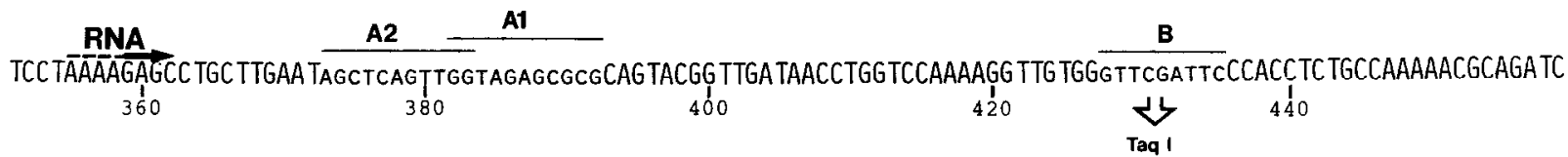

B)

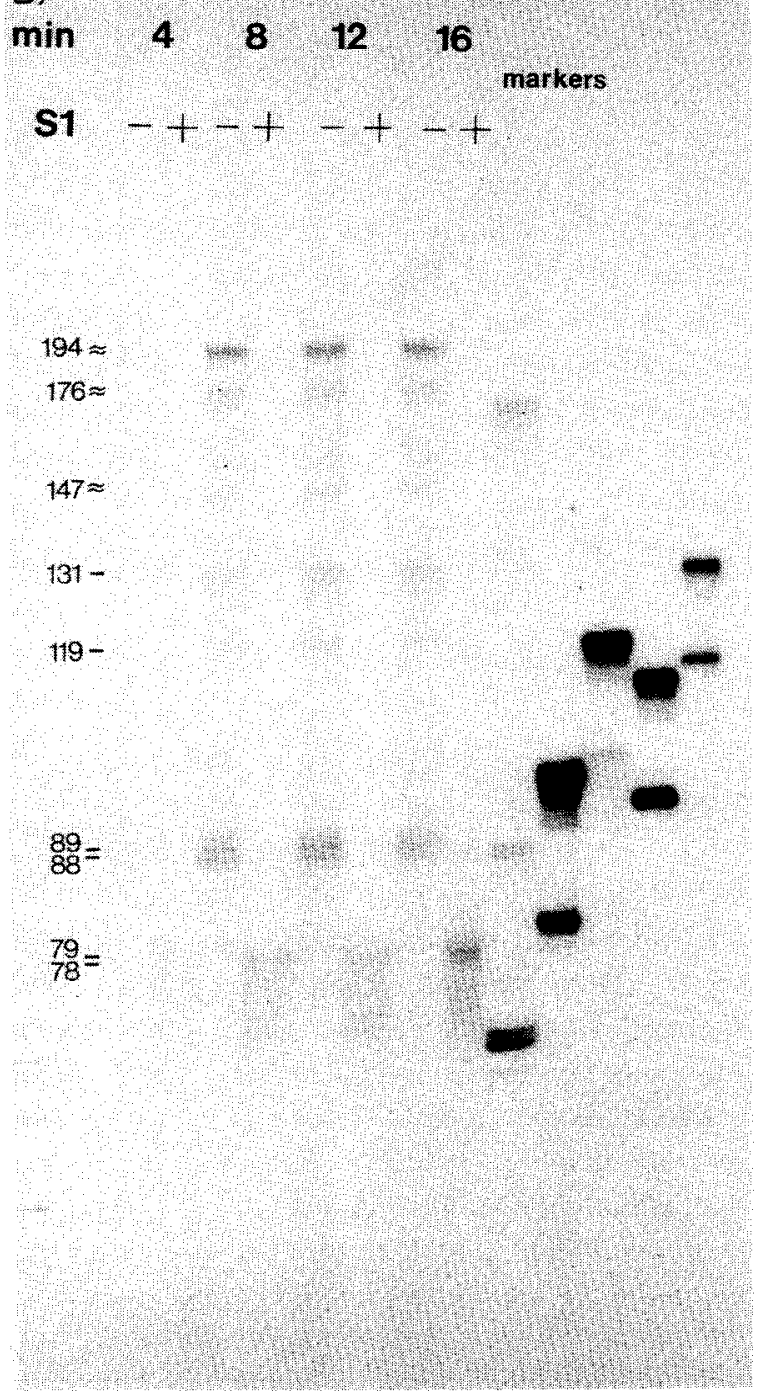

Fig. 1. Time course of pE190 transcription by the nuclear extract and S1 nuclease analysis of RNA. (A) The structure and sequence of plasmid pE190 containing a satellite I DNA repeat in the HindIII site of pBR322 has been published previously (Lam and Carroll, 1983). The nucleotide sequence of the nontemplate strand is shown in the region containing the major transcription start points and the RNA polymerase III promoter consensus sequences (small caps). In addition to the A block promoter consensus (PuPuPyNNAPuPyGG) noted earlier (region A2, Wakefield et al., 1983; Andrews et al., 1983) a second region of lesser homology is indicated (A1). A probe for S1 nuclease analysis of the RNA transcripts from this region was prepared by cloning the fragment extending from the left-hand $H$ indIII site to the indicated TaqI site between the HindIII and $A c c$ I sites of M13mp18 virus. Viral DNA contained a single DNA strand complementary to the sequence shown. (B) Plasmid pE190 was transcribed by the $S$.cerevisiae extract in the presence of $\left[\alpha^{-32} \mathrm{P}\right] \cup \mathrm{I} \boldsymbol{P}$ for $3 \mathrm{~min}$, after which a 50 -fold excess of unlabeled UTP was added to quench the incorporation of label, and the incubations continued an additional $8 \mathrm{~min}$. Aliquots were taken for analysis at 4,8,12 and $16 \mathrm{~min}$ after the addition of extracts. The low level of transcripts seen after $4 \mathrm{~min}$ is typical of the 1.5-3-min lag in transcription initiation (Engelke et al., 1985). The subsequent transcription initiation rate was estimated to be greater than 0.6 transcripts per gene per min by determining Cherenkow radiation in the product bands. Radiolabeled E190 RNA aliquots were either analyzed directely by size ('minus' S1 lanes) or first prc-incubatcd with $10 \mu \mathrm{g}$ unlabeled, single stranded, viral S1 probe (panel A) and treated with S1 nuclease ('plus' S1 lanes) prior to electrophoretic analysis. The surviving RNA showed a major start point $78 \mathrm{nt}$ upstream from the Taq I site and other products up to $8 \mathrm{nt}$ shorter. The positions of these initiation sites are shown relative to the $\mathrm{A}$ and $\mathrm{B}$ block sequences in panel A. The sizes of the RNA transcripts, shown in nt to the left of the panel, were determined by using as standards the precursor and end-matured forms of (left to right in "markers' lanes): tRNA ${ }^{\text {Arg/Asp }}$ (71 to $170 \mathrm{nt}$; Engelke et al, 1985) and four pairs of tRNA ${ }^{\text {Leu }}$ with various lengths deleted from the inter- 
block consensus. Here the association between partially purified RNA polymerase III transcription factor TFIIIC (Engelke et al., 1985; Huibregtse et al., 1987) and the promoter elements is shown to be characteristic of a tRNA-like transcription unit.

\section{EXPERIMENTAL AND DISCUSSION}

\section{(a) Satellite I DNA transcription in vitro}

The monomer clone of satellite I DNA used in these experiments, pE190, has been described previously (Lam and Carroll, 1983; gift of Dana Carroll, University of Utah). The structure of the 741-bp repeat is shown in Fig. 1A along with the nucleotide sequence in the region of the A block and B block RNA polymerase III promoters. In addition to the A2 consensus sequence noted previously (Ackerman, 1983; Andrews et al., 1984) a second overlapping region of lesser homology to the $\mathrm{A}$ consensus is indicated (A1). The ability of these sequences to efficiently bind the tRNA promoter recognition factor, TFIIIC, could be tested using transcription factor fractions isolated from yeast nuclei (Huibregtse et al., 1987) because recognition of the tightly conserved tRNA gene internal promoters by

vening sequence ( 99 to 81,118 to 100,112 to 94,131 to $133 \mathrm{nt}$; Strobel and Abelson, 1986). Uncertainty in the exact assignment of $\mathrm{pE} 190$ transcript sizes longer than $131 \mathrm{nt}$ was due to the relatively small number of longer markers. Methods: Plasmid templates pE190 and pUCtRNA ${ }^{\text {Leu }}-\Delta$ IVS and preparation of S.cerevisiae transcription extracts have been described (Lam and Carroll, 1983; Strobel and Abelson, 1986; Huibregtse et al., 1987). Transcription time-course reactions were assembled in $100 \mu 1$ containing $50 \mathrm{mM}$ HEPES $(N-2-$ hydroxyethylpiperizine- $N^{\prime}$-2-ethanesulfonic acid, $\mathrm{pH}$ 7.9), 120 $\mathrm{mM} \mathrm{KCl}, 8 \mathrm{mM} \mathrm{MgCl}_{2}, 0.2 \mathrm{mM}$ dithiothreitol, $1 \mathrm{mM}$ phosphoenolpyruvate, $200 \mu \mathrm{M}$ each ATP, GTP and CTP, $20 \mu \mathrm{M}$ UTP including $10 \mu \mathrm{Ci}\left[\alpha_{-}{ }^{32} \mathrm{P}\right] \mathrm{UTP}$ (New England Nuclear), $2.5-4 \mu \mathrm{g}$ plasmid template and $20 \mu \mathrm{l}$ yeast extract. $20 \mu \mathrm{l}$ aliquots were withdrawn at the indicated times, stopped and digested for $90 \mathrm{~min}$ at $50^{\circ} \mathrm{C}$ with the addition of $4 \mu 1$ stop $\operatorname{mix}[1 \mathrm{mg} / \mathrm{ml}$ proteinase $\mathrm{K}$ (Beckman), 2\% SDS, $100 \mathrm{mM}$ EDTA, pH 8.0] and precipitated with ethanol. Ten $\mu \mathrm{g}$ of viral S1 probe DNA was annealed to one-half of the RNA from each time point and digested for $30 \mathrm{~min}$ at $18^{\circ} \mathrm{C}$ with 10 units of $\mathrm{S} 1$ nuclease. Reactions were halted with stop mix, precipitated with ethanol and analyzed by size on denaturing 10\% PA gels (Engelke et al., 1985). transcription components from evolutionarily distant species is known to occur efficiently (Sprague et al., 1980; Dingermann et al., 1982). Although the physiological significance of satellite I DNA transcription by heterologous or even homologous extracts is uncertain (see section d), transcription of the E190 sequences was characterized to ensure that factor-DNA complexes potentiated transcription initiation upstream from the promoter sites in a manner similar to that observed using homologous components.

Transcription of the satellite I repeat routinely produced multiple RNA species of 87 to approx. $194 \mathrm{nt}$, consistent with the multiple transcripts observed previously with Xenopus extracts (Andrews et al., 1984). To map the transcription start point(s) and to test for the possibility that the various bands arise from nucleolytic RNA processing, a pulsechase time course of transcription was performed (Fig. 1B). One-half of the RNA products from each time point were analyzed directly by size ( $-\mathrm{S} 1$ lanes) and showed no obvious precursor-product relationship among the bands. Since tRNA precursors from both yeast and Xenopus are subject to removal of their $5^{\prime}$ and $3^{\prime}$ termini and to splicing in this extract (Newman et al., 1983; Engelke et al., 1985; Strobel and Abelson, 1986), this observation suggests that the E190 transcripts do not contain tertiary structure appropriate for recognition by pre-tRNA processing enzymes.

To identify the transcription start point(s) the other half of the radiolabeled pE190 transcripts from each time point were annealed to single-stranded M13 viral DNA containing as an insert the template strand between the leftward HindIII site and the TaqI site within the B block. Digestion with S1 nuclease (+ S1 lanes) gave protected RNA fragments consistent with transcription initiation within a run of five A residues upstream of the A blocks (indicated in Fig. 1A). The heterogeneity observed in the $5^{\prime}$ terminus probably represents true heterogeneity in initiation since the only major runoff transcripts when the pE190 template is truncated downstream of the B block also correspond to diffuse initiations in this region (D.R.E., unpublished observation). The longest of these transcripts initiates $4 \mathrm{bp}$ upstream from the transcription start point observed in Xenopus, but this difference was not unexpected given that heterologous transcription extracts fre- 
quently do not recognize upstream promoter sequences (Sprague et al., 1980; Dingermann et al., 1982). The longest transcript (approx. $194 \mathrm{nt}$ ) corresponds to transcription termination at the first RNA polymerase III terminator (five $T$ residues) $108 \mathrm{nt}$ downstream from the B block. The reason for the apparent transcription pauses or terminations giving rise to the shorter trancripts was not obvious from inspection of the nucleotide sequence.

\section{(b) Competion between satellite I DNA and tRNA genes for transcription factors}

Template exclusion assays (Fuhrman et al., 1984; Baker and Hall, 1984) were performed to aftirm the ability of the satellite I DNA to stably bind tRNA gene transcription components and the requirement for such binding in transcription. A tRNA gene with a strong in vitro promoter, tRNA ${ }^{\mathrm{Leu}}$ (SUP53) with a deleted intervening sequence (Strobel and Abelson, 1986), was added to the extract either in increasing amounts before the addition of pE190 (Fig. 2, lefthand lanes) or after increasing concentrations of pE190 had been preincubated with the extract (righthand lanes). DNA concentration was held constant by the inclusion of plasmid vector pUC9 in the reactions. In both cases transcription of the second template by $4 \mu 1$ of extract was excluded more than $50 \%$ by $60 \mathrm{fmol}$ of the first template and entirely excluded by $260 \mathrm{fmol}$. Thus, even though transcription initiation on the E190 DNA by RNA polymerase III was routinely only $10 \%$ to $20 \%$ as frequent as transcription of the tRNA gene, both templates efficiently bound one or more required transcription factors into stable complexes. The reason for the difference in initation frequency between the two templates is not clear, but may be related to the lack of appropriate yeast transcription signals upstream from the E190 internal promoter region (Johnson and Raymond, 1984).

\section{(c) Transcription factor IIIC binds to the bipartite internal promoter}

To identify the sites of transcription attachment, partially purified transcription factors TFIIIB and TFIIIC (Engelke et al., 1980; Segall et al., 1980; Fuhrman et al., 1984) containing no detectable cross-contamination (Huibregtse et al., 1987) were used in DNase I footprinting experiments with either satellite I DNA or the tRNA $^{\text {Leu- }}$ IIVS gene (Fig. 3A). As observed previously for the tRNA ${ }^{\mathrm{Leu}}$ gene (Klemenz et al., 1982; Stillman et al., 1985; Huibregtse et al., 1987), TFIIIC afforded DNase I protection at the A and B blocks of both DNAs in the presence or absence of TFIIIB. The extent of this protection relative to the internal promoter sequences is depicted in Fig. 3B. The A2 sequence is likely to be the one primarily used for binding the transcription factor(s) since the upstream DNase I protection is centered over this region, similar to the case for the tRNA gene footprints (Stillman et al., 1984; Huibregtse et al., 1987). This conclusion is reinforced by the fact that the E190 transcription start points are approximately the same distance upstream from the A2 consensus as the tRNA start points are from the tRNA A block. We cannot, however, rule out the possibility that the $\mathrm{A} 1$ sequence plays some role in the efficiency of factor binding or transcription initiation. Evidence for protection being due to the identical factor(s) binding to both DNAs was provided by preincubation of the factors with an unlabeled excess ( $260 \mathrm{fmol}$ ) of pE190 DNA competitor in tRNA gene footprinting reactions or of ptRNA ${ }^{\text {Leu-}}$ - IVS DNA competitor in E190 footprinting reactions (Fig. 3A, ' + ' competitor DNA lanes).

\section{(d) Significance}

The functions of Xenupus satellite I DNA in vivo are obscure. Examination of endogenous RNA from oocytes, embryos and somatic cells has shown, at best, low levels of satellite I transcripts (Wakefield et al., 1983). The lack of highly reiterated satellite I DNA in $X$. borealis and $X$. mulleri (Lam and Carroll, 1983) also argues that the majority of the repeats are entirely dispensable. One possible explanation for these observations is that this RNA is expressed only in a tissue or during a developmental stage not yet examined and that only a small number of repeats need be activated. Alternatively, several explanations for the presence of reiterated RNA polymerase III promoter elements have been suggested that assume recognition by site-specific DNA binding proteins, but that do not necessarily require the production of stable RNA products (Jelinek and Leinwand, 1978; Van Arsdell et al., 1981; Jagadees- 


\section{1st DNA \\ tRNA \\ E190 \\ fmoles \\ $0 \quad 1030601202600 \quad 103060120260$}
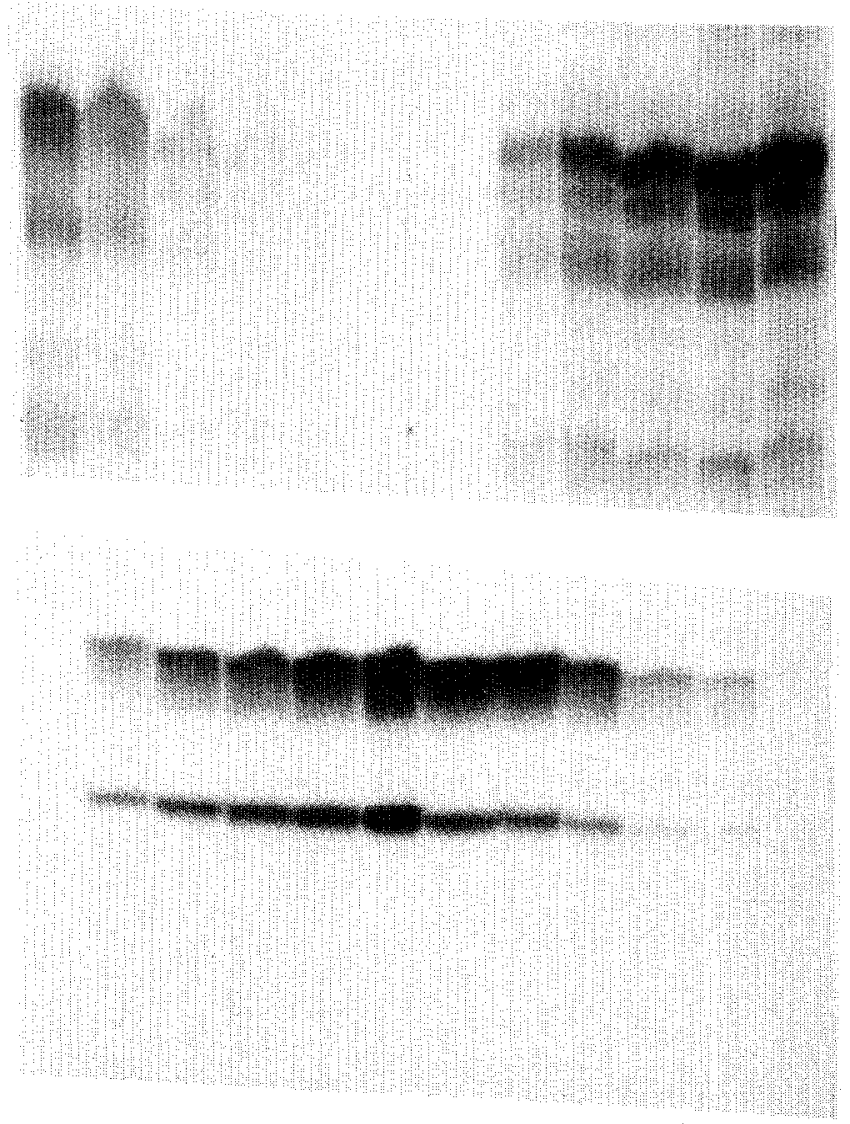

\section{2nd DNA \\ (220 fmoles)}

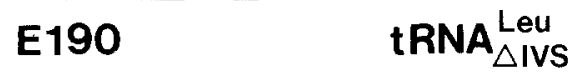

Fig. 2. Mutual template exclusion by E190 and tRNA ${ }^{\text {Leu }}$ DNA. Transcription reactions were performed as described in Fig. 1 except that individual 20- $\mu 1$ reactions were assembled with the first template indicated in the absence of $\left[\alpha-{ }^{32} \mathrm{P}\right] \mathrm{UTP}$ and incubated at $30^{\circ} \mathrm{C}$ for $3 \mathrm{~min}$. Plasmid pUC9 was added to the reactions to equalize the DNA concentration at $30 \mu \mathrm{g} / \mathrm{ml}$. After the preincubation, $220 \mathrm{fmol}$ of the second plasmid template and $\left[\alpha-{ }^{32} \mathrm{P}\right] \mathrm{UTP}$ were added. Incubations continued for $15 \mathrm{~min}$ before the reactions were stopped and RNA analyzed by electrophoresis through denaturing 10\% PA gels (Sanger and Coulson, 1978). The data shown were derived from two radioautography exposures of the same gel for $12 \mathrm{~h}$ (lower panel) or $40 \mathrm{~h}$ (upper panel) to adjust for differences in transcription efficiency. The tRNA ${ }^{\text {Leu }}-\Delta$ IVS gene was chosen for this experiment because both the primary transcript (upper band, lower panel) and the end-matured processing product (lower band, lower panel) migrated faster than all of the pE190 transcripts (upper panel).

waran et al., 1981; Sutcliffe et al., 1984; Andrews et al., 1984). The results presented here show that the RNA polymerase III transcription factor TFIIIC binds tightly to the satellite I A block and B block promoter sequences without mediation by Xenopus satellite I-specific components. This suggests that whatever function the satellite I sequences play may be mediated by the same class of factor that forms stable complexes with the tRNA genes. 


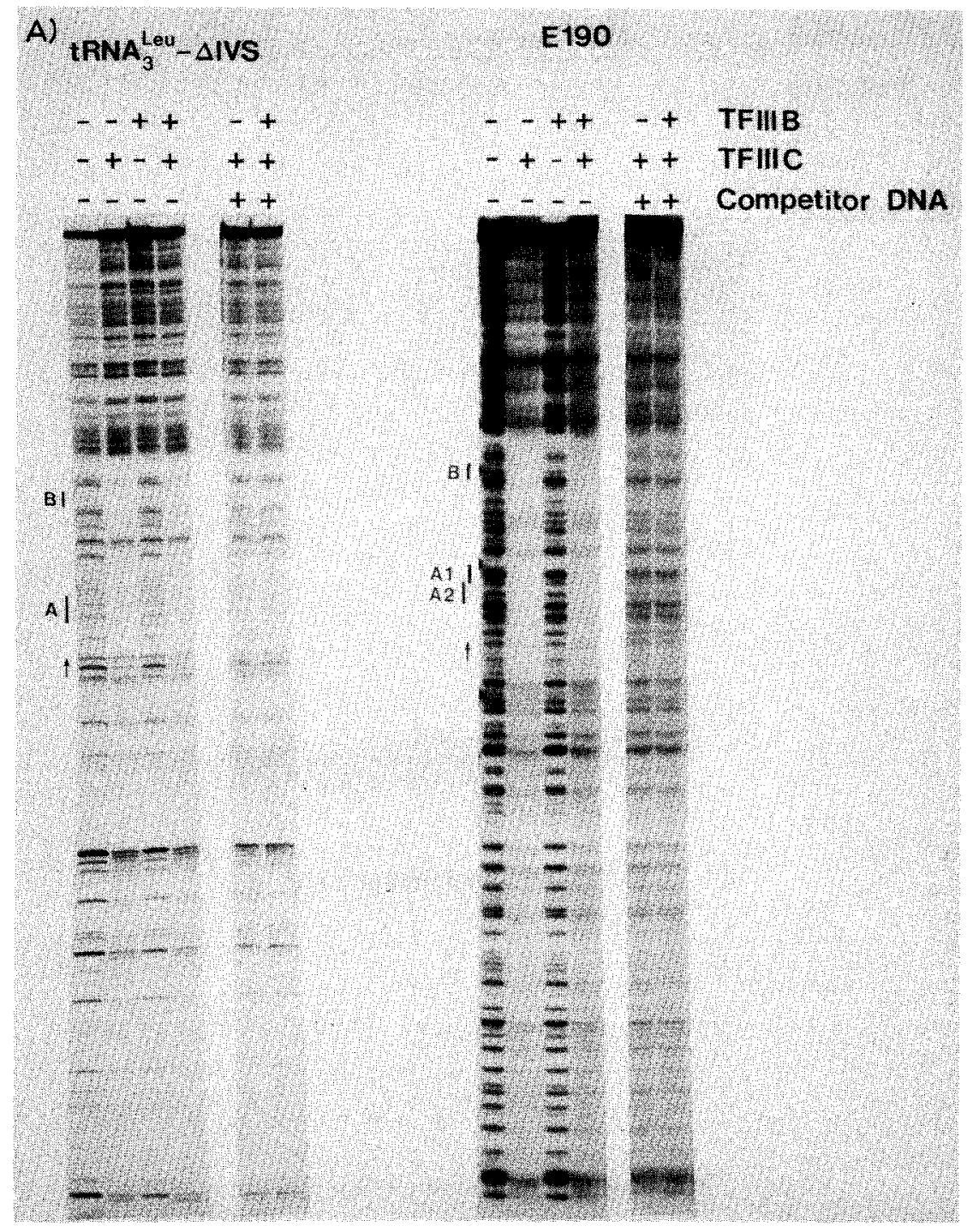

B

tRNA $_{3}^{\text {Leu }}-\Delta$ IVS

A

B

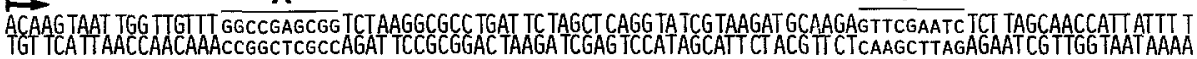

\section{E 190}

A2 A1

B

Fig. 3. DNase I protection of A and B block promoter sequences by transcription factors TFIIIB and TFIIIC. (A) DNase I footprinting (Galas and Schmitz, 1978) was performed using tRNA gene transcription factors TFIIIB and TFIIIC. Where the inclusion of competitor DNA is indicated, the pUC9 carrier was replaced with either $260 \mathrm{fmol}$ of plasmid pE190 in the tRNA gene footprinting or 260 fmol of plasmid pUCtRNA ${ }^{\text {Leu }}-\Delta$ IVS in the E190 DNA footprinting. For both the tRNA ${ }^{\text {Leu }}-\Delta$ IVS gene and the E190 DNA the positions of the $A$ and $B$ blocks are indicated to the left of the panels. Arrows to the left of each panel indicate the position and direction of transcription initiation. Protection of the tRNA gene promoters is essentially in agreement with previous reports (Klemenz et al., 1982; Stillman et al., 1985; Huibregtse et al., 1987). The reason for minor differences in the DNase I digestion profile outside the tRNA gene in the absence 


\section{ACKNOWLEDGEMENTS}

I am grateful to Barbara Hamkalo and Joel Gottesfeld for advice and encouragement, to Dana Carroll, Marjorie Strobel and John Abelson for gifts of plasmid DNA, and to Claire Evans for critique of the work and manuscript. Supported by National Science Foundation research grant numbers PCM8302828 and DBM-8603115.

\section{REFERENCES}

Ackerman, E.J.: Molecular cloning and sequencing of OAX DNA: an abundant gene family transcribed and activated in Xenopus oocytes. EMBO J. 2 (1983) 1417-1422.

Andrews, D.L., Millstein, L., Hamkalo, B.A. and Gottesfeld J.M.: Competition between Xenopus satellite I sequences and pol III genes for stable transcription complex formation. Nucl. Acids Res. 12 (1984) 7753-7769.

Baker, R.E. and Hall, B.D.: Structural features of yeast tRNA genes which affect transcription factor binding. EMBO J. 3 (1984) 2793-2800.

Dingermann, T., Burke, D.J., Sharp, S., Schaak, J. and Söll, D.: The 5' flanking sequences of Drosophila tRNA ${ }^{\text {Arg }}$ genes control their in vitro transcription in a Drosophila cell extract. J. Biol. Chem. 257 (1982) 14738-14744.

Duncan, C., Biro, P.A., Choudary, P.V., Elder, J.T., Wang, R.R.C., Forget, B.G., De Riel, J.K. and Weissman, S.M.: RNA polymerase III transcriptional units are interspersed among human non- $\alpha$-globin genes. Proc. Natl. Acad. Sci. USA 76 (1979) 5095-5099.

Elder, J.T., Pan, J., Duncan, C.H. and Weissman, S.M.: Transcriptional analysis of interspersed repetitive polymerase III transcription units in human DNA. Nucl. Acids Res. 9 (1981) 1171-1189.

Engelke, D.R., Gegenheimer, P. and Abelson, J.: Nucleolytic processing of a tRNA ${ }^{\text {Arg }}$-tRNA ${ }^{\text {Asp }}$ dimeric precursor by a homologous component from Saccharomyces cerevisiae. J. Biol. Chem. 260 (1985) 1271-1279.

Engelke, D.R., Ng, S.-Y., Shastry, B.S. and Roeder, R.G.: Specific interaction of a purified transcription factor with an internal control region of 5S RNA genes. Cell 19 (1980) 717-728.

Fritsch, E.F., Sehn, C.-K. J., Sawn, R.M. and Maniatis, T.: The organization of repetitive sequences in mammalian globin gene clusters. Cold Spring Harbor Symp. Biol. 45 (1981) 761-765.

Fuhrman, S.A., Deininger, P.L., LaPort, P., Friedmann, T. and Geiduschek, E.P.: Analysis of transcription of the human Alu family ubiquitous repeating element by eukaryotic RNA polymerase III. Nucl. Acids Res. 9 (1981) 6439-6456.

Fuhrman, S.A., Engelke, D.R., and Geiduschek, E.P.: HeLa cell RNA polymerase III transcription factors. J. Biol. Chem. 259 (1984) 1934-1943.

Galas, D. and Schmitz, A.: DNase footprinting: a simple method for the detection of protein-DNA binding specificity. Nucl. Acids Res. 5 (1978) 3157-3170.

Huibregtse, J.M., Evans, C.F. and Engelke, D.R.: Comparison of tRNA gene complexes formed in vitro and in nuclei. Mol. Cell. Biol. 7 (1987) 3212-3220.

Jagadeeswaran, P., Forget, B.G. and Weissman, S.M.: Short interspersed repetitive DNA elements in eukaryotes: transposable DNA clements generated by reserve transcription of RNA pol III transcripts. Cell 26 (1981) 141-142.

Jelinek, W. and Leinwand, L.: Low molecular weight RNAs hydrogen-bonded to nuclear and cytoplasmic poly(A)-terminated RNA from cultured chinese hamster ovary cells. Cell 15 (1978) 205-214.

Johinson, J.D. and Raymond, G.J.: Three regions of a yeast tRNA $^{\text {Leu }}$ gene promote RNA polymerase III transcription. J. Biol. Chem. 259 (1984) 5990-5994.

or presence of the TFIIIC fraction is unknown. The differences were not removed by the inclusion of specific competitor DNA and similar effects have been seen with DNA fragments not harboring RNA polymerase III promoters (not shown). (B) Minimum regions of satellite I DNA and TRNA gene protected by the presence of TFIIIC are indicated by solid lines below the sequence. In regions where no cleavages exist in the naked DNA controls, positions between protected cleavages have been assigned as protected. Positions between a protected and non-protected cleavage have been assigned as unprotected. E190 DNA between the A and B regions was reproducibly subject to reduced DNase I cleavage (dotted line), but not to full protection. Major transcription start points are indicated by arrows. Methods: Fractionation of yeast tRNA gene transcription factors TFIIIB and TFIIIC is described elsewhere (Huibregtse et al., 1987). Linear DNA fragments containing satellite I (E109) DNA or the IRNA ${ }^{\text {Leu }}-\Delta I V S$ gene were end-labeled by filling in restriction site overhangs with $\left[\alpha{ }^{32} \mathrm{P}\right] \mathrm{dATP}$ (New England Nuclear) using the Klenow fragment of $E$. coli DNA polymerase I (Bethesda Research Laboratories). E190 fragment from a SmaI-HindIII subclone of E190 (inserted between the SmaI and HindIII sites of the pUC9 polylinker) was labeled 225 bp uspstream from the A2 sequence at the vector $E c o$ RI site. The tRNA gene fragment was labeled 240 bp upstream from the A block promoter at the vector $E c o$ RI site. Footprinting reactions were performed as described by Newman et al. (1983) with minor modifications. Binding reactions were carried out at $22^{\circ} \mathrm{C}$ for $10 \mathrm{~min}$ using $10 \mathrm{fmol}$ of labeled DNA fragment, $0.8 \mu \mathrm{g}$ of plasmid pUC 9 carrier or plasmid competitor and enough of the indicated transcription factor (TFIIIB or TFIIIC) to saturate an in vitro transcription reaction containing 125 fmol of tRNA gene. DNase I (Worthington) was added to a final concentration of $1.0 \mu \mathrm{g} / \mathrm{ml} \mathrm{for} 30 \mathrm{~s}$ at $22^{\circ} \mathrm{C}$. The reactions were halted with stop mix and the DNA was ethanol-precipitated and subjected to electrophoresis through denaturing $10 \%$ polyacrylamide gels (Sanger and Coulson, 1978). Restriction endonuclease cleavages and nucleotide sequencing reactions using the end-laheled DNAs were used as markers to determine the positions of DNase I cleavages. 
Klemenz, R., Stillman, D.J. and Geiduschek, E.P.: Specific interactions of Saccharomyces cerevisiae proteins with a promoter region of eukaryotic tRNA genes. Proc. Natl. Acad. Sci. USA 79 (1982) 6191-6195.

Lam, B.S. and Carroll, D.: Tandemly repeated DNA sequences from Xenopus laevis. J. Mol. Biol. 165 (1983) 567-585.

Newman, A.J., Ogden, R.C. and Abelson, I.: tRNA gene transcription in yeast: effects of specified base substitutions in the intragenic promoter. Cell 35 (1983) 117-125.

Perez-Stable, C., Ayres, T.M. and Shen, C.-K.: Distinctive sequence organization and functional programming of an $\mathrm{Alu}$ repeat promoter. Proc. Natl. Acad. Sci. USA 81 (1984) 5291-5295.

Sanger, F. and Coulson, A.R.: The use of thin acrylamide gels for DNA sequencing. FEBS Lett. 87 (1978) 107-110.

Segall, J., Matsui, T. and Roeder, R.G.: Multiple factors are required for the accurate transcription of purified genes by RNA polymerase III. J. Biol. Chem 255 (1980) 11986-11991.

Sharp, S., DeFranco, D., Dingermann, T., Farrell, P. and Soll, D.: Internal control regions for transcription of eukaryotic tRNA genes. Proc Natl. Acad. Sci. USA 78 (1981) 6657-6661.

Sprague, K.U., Larson, D. and Morton, D.: 5 ' flanking sequence signals are required for activity of silkworm alanine tRNA genes in homologous in vitro transcription systems. Cell 22 (1980) 171-178.
Stillman, D.J. and Geiduschek, E.P.: Differential binding of a Saccharomyces cerevisiae RNA polymerase III transcription factor to two promoter elements of a tRNA gene. EMBO J. 3 (1984) 847-853.

Stillman, D.J., Caspers, P. and Geiduschek, E.P.: Effect of singlestranded DNA on the interaction of an RNA polymerase III transcription factor with a tRNA gene. Cell 40 (1985) 311-317.

Strobel, M.C. and Abelson, J.: Effect of intron mutations on processing and function of Saccharomyces cerevisiae SUP53 tRNA in vitro and in vivo. Mol. Cell. Biol. 6 (1986) 2663-2673.

Sutcliffe, J.G., Milner, R.J., Gottesfeld, J.M. and Lerner, R.A.: Identifier sequences are transcribed specifically in brain. Nature 308 (1984) 237-241.

Van Arsdell, S.W., Denison, R.A., Bernstein, L.B., Weiner, A.M., Manser, T. and Gesteland, R.F.: Direct repeats flank three small nuclear RNA pseudogenes in the human genome. Cell 26 (1981) 11-17.

Wakefield, L., Ackemann, E.J. and Gurdon, J.B. : The activation of RNA synthesis by somatic nuclei injected into amphibian oocytes. Develop. Biol. 95 (1983) 468-475.

Communicated by M.R. Culbertson. 